\title{
Optimization of technology for production of products of deep drawing sheet steels with the use of lubricants in universal software system ANSYS workbench
}

\author{
Gennady I. Shulga*, Alex O. Kolesnichenko, Paul V. Sirotin, Ilya Yu. Lebedyns'kyi, \\ Eugene V. Skrynnikov, and Maxim A. Vasilyev \\ Platov South-Russian State Polytechnic University (NPI), 346400 Novocherkassk, Russia
}

\begin{abstract}
The techniques and laboratory tests, simulating the technological process of drawing sheet steels with water soluble lubricant PB-18 with a fractal structure, with the addition of nanopowders of copper and bronze. Given optimization of the stretching process of sheet steels using universal software system of finite-element analysis ANSYS Workbench
\end{abstract}

\section{Introduction}

In modern engineering are widely spread getting axisymmetric parts made of sheet steel with the use of low-waste technological processes of stamping and extrusion. Development of science-based technologies for the production of products by stamping and hood using water-soluble lubricants containing a fractal structure, ensuring high quality deformable surface, improving the life of punching tools, the optimization of these processes with the use of universal program system of finite element analysis ANSYS Workbench is an actual scientific and technical problem.

This problem is solved by developing and using the technology of water-soluble lubricant ER-18, which include a hybrid ligand of fractal clusters with nanometric particle powders of non-ferrous metals.

Hybrid clusters are formed in the contact zone of self-organizing dissipative structures comprising a discrete composite film of desired thickness. These films consist of silicon oxide, surfactants, nano-powders of non-ferrous metals, providing increased load capacity, durability, punching tools, reduction of power parameters of technological process and improve the quality of machined surfaces [1,2].

Based on the generalized law of friction during plastic deformation V. E. Isachenkova, E. I. Isachenkova [3], the specific force of friction in plastic deformation is determined:

$$
\tau=\mu_{D T} \cdot q \cdot(1-\gamma)+\eta \cdot \frac{d V}{d z} \cdot \gamma,[3]
$$

\footnotetext{
* Corresponding author: g.shulga41@mail.ru
} 
where $\tau$ - specific force of friction on the boundary of a deformable material-tool, $\mathrm{N} / \mathrm{mm}^{2}$; $\mu_{D T}-$ the coefficient of dry sliding friction;

$q$ - contact specific load, $N / \mathrm{mm}^{2}$;

$\gamma=\frac{S_{O}}{S_{C}}-$ the ratio of the continuity of the lubricant between the rubbing surfaces of the processed material and the tool;

realized in dry friction when $-\gamma=0$, when $-1>\gamma>0$ boundary friction, hydrodynamic friction when $-\gamma=1$;

$S_{O}-$ the area of lubricated contact surface, $\mathrm{mm}^{2}$;

$S_{C}$ - the whole area of the contact surface, $\mathrm{mm}^{2} ; \eta$ - dynamic viscosity of the lubricant, $\mathrm{P}$

$V$ - sliding speed in the contact zone, $\mathrm{mm} / \mathrm{c} ; Z$-the average value of the lubricating layer; mm.

Based on the theory of friction of Bowden welding, cut and ploughing [4] the coefficient of friction without the lubricant, determine:

$$
\mu_{D F}=\mu_{A}+\mu_{D}=K_{A} \cdot \frac{S_{s s .}}{p^{*}}+\frac{A_{2}}{A_{1}},
$$

where $\mu_{A}$ - the adhesion component of the friction coefficient;

$\mu_{D}$ - deformation component of friction;

$K_{A}$-coefficient depending on the shape of the model of roughness adopted in the calculation (sphere, horizontal cylinder, cone);

$S_{s s}$-average acting shear stress, $\mathrm{N} / \mathrm{mm}^{2}$;

$p^{*}$ - yield strength of the deformed material, $\mathrm{N} / \mathrm{mm}^{2}$;

$A_{1}$ - square grooves ploughing, the load, $\mathrm{mm}^{2}$;

$A_{2}$ - the cross - sectional area of the groove, $\mathrm{mm}^{2}$.

Substituting equation (2) into (1), we obtain the specific power of friction during plastic deformation:

$$
\tau=\left(K_{A} \cdot \frac{S_{s s}}{p^{*}}+\frac{\mathrm{A}_{2}}{\mathrm{~A}_{1}}\right) \cdot q \cdot(1-\gamma)+\eta \cdot \frac{d V}{d z} \cdot \gamma
$$

In case of boundary friction the total friction consists of a liquid, adhesion and deformation components:

$$
\mu_{B F}=\mu_{L}+\mu_{A}+\mu_{D}=S_{L} \cdot \gamma+\frac{S_{s s}}{\bar{p}}(1-\gamma)+\frac{F_{p r}}{S_{C} \cdot \bar{p}}(1-\gamma)
$$

$\mu_{L}$ - the liquid component of the friction coefficient;

$S_{L}$ - the shear resistance of the lubricant in , N/ $\mathrm{mm}^{2}$;

$\bar{p}$ - the average pressure, $\mathrm{N} / \mathrm{mm}^{2}$;

$p^{*}>\bar{p}>p_{\text {hydr }}$ 
$p_{\text {hydr }}$ - hydrodynamic pressure in the cavities of the roughness $\mathrm{N} / \mathrm{mm}^{2}$;

$F_{p r}-$ the power of prophylene, N.

An important element when using finite element analysis ASYS Workbench is a preliminary determination of the coefficient of friction between the materials of article to be deformed and die tool with the application of technological lubricants.

\section{Materials and methods}

Determination of the tribological properties of friction pair steel $40 \mathrm{X}$ sheet steel $08 \mathrm{JU}$ using technological lubricant PB-18 with the additives of nano-powders of non-ferrous metals of copper, bronze and Nickel carried on the end car of friction. As the cylindrical specimen with an external diameter of $15 \mathrm{~mm}$, an inner diameter of $10 \mathrm{~mm}$, a height of $25 \mathrm{~mm}$ used steel 40X, simulating the stamping tool, as wrought products used the plate with thickness $1.5 \mathrm{~mm}$, diameter $30 \mathrm{~mm}$, made of steel 08JU.

Determination of anti-wear, anti-friction properties of $40 \%$ aqueous solution of the technological lubricant PB-18 with the additives of nano-powders of copper, bronze and Nickel was performed at a spindle rotation frequency $n=47,3$ min-1 (linear velocity of 0,01 $\mathrm{m} / \mathrm{s}$ ). A unit load was changed from 0.05 to $1 \mathrm{MPa}$. The magnitude of wear of the cylindrical sample and the plates was determined by weighing on an analytical balance SE$224 \mathrm{C}$ according to GOST 5322-2008 [5].

Evaluation of the effectiveness of a $40 \%$ aqueous solution of RE-18 with a hood of sheet steel produced on a machine for testing the technological properties of sheet metal hydraulic MTS-10H-1 [6] with the following modes: load change at the hood of 0.3-10 the vehicle, the speed of movement of the punch with a $4.0-24.0 \mathrm{~mm} / \mathrm{min}$, the range of movement of the punch $20.0 \mathrm{~mm}$. As deformable workpieces using samples of sheet steel St3kp, 08kp, 08JU diameter $48 \mathrm{~mm}$, thickness 0,8-3 mm.

Criteria of estimation of efficiency of lubricating material RE-18 are: stress corresponding to the yield strength of the material of the sample $P_{s}, \mathrm{kN}$; the maximum force of rupture of the specimen $P_{r \max }, k N$; the average diameter of the flange after drawing, $D_{f a}$, $\mathrm{mm}$; the ratio of the ultimate strain $K_{u s}$; the difference between the blank diameter and flange, $\Delta D, \mathrm{~mm}$; the coefficient of relative ultimate strain $K_{r u s}$; the depth of extraction $H_{d e}, \mathrm{~mm}$, the relative depth of extraction $H_{r d e}, \%$.

\section{Results and discussion}

For optimization of technological process of deep drawing sheet steels with water soluble lubricant RE-18 with the additives of nano-powders of non-ferrous metals determined the friction coefficient of the matrix of stamping tool of $40 \mathrm{H}$ steel and sheet steel $08 \mathrm{JU}$. Tests on the end car of friction of $40 \%$ aqueous solution of the lubricant RE- 18 without additives and with additives $1-2 \%$ of nano-powders of copper, bronze, zinc showed (Fig.1) change the coefficient of friction couples $40 \mathrm{~S}$ - steel $08 \mathrm{JU}$ from 0.12 to 0.16 when specific loads $p=30 \ldots 100 \mathrm{MPa}$. Coefficient of friction $\mu=0,150,16 .$. was adopted in the computer model in ASYS Workbench upon receipt of an axisymmetric sheet hood. 


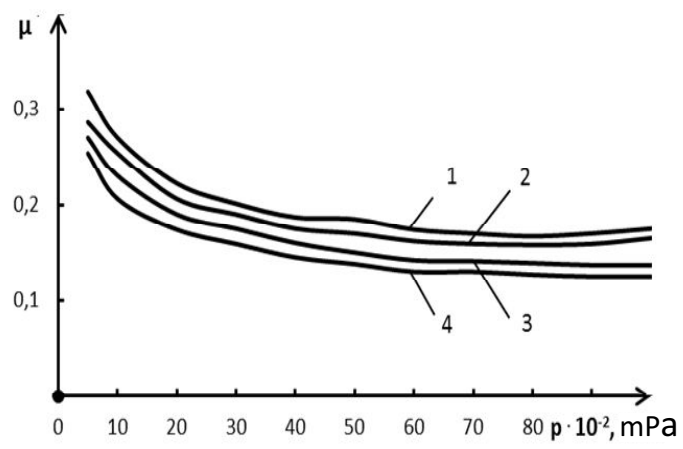

Fig.1. the dependence of the friction coefficient of the specific pressure of the lubrication of friction pair steel 40X-steel 08JU; 1 -RE-18; 2 - RE-18 with the addition of $1 \%$ of the nanopowder of bronze; $3-\mathrm{RE}-18$ with the addition of $2 \%$ of nano powder of zinc; 4 - RE- 18 with the addition of $2 \%$ of the nanopowder of copper.

Comparative tests of technological lubricating material on the machine for testing the technological properties of sheet metal hydraulic MTS-10H-1 (tab.1.) showed that $40 \%$ aqueous solution of RE-18 with the addition of $2 \%$ of the nanopowder of copper showed the best results according to the criteria of efficiency compared to the stamping lubricant SL-2M TU 0254-044-23763315-2006 and technical castor oil GOST 6757-96 [7].

Modeling of technological process of deep drawing in the software package of finite element analysis ANSYS Workbench for steel workpieces: St3kp, 08KP, 08JU, physical and mechanical properties are shown in table.2. The influence of $40 \%$ of the lubricant RE18 with the addition of colored powders on the efficiency of the process on the following criteria: maximum drawing depth before the rupture, the maximum stress occurring in the sample throughout the studied process.

The geometric parameters of the model die of the tool for deep drawing sheet steels with a clamp shown in Fig.2. The main elements of the stamping tool are: the matrix 1, the blank 2 is pressed against the matrix clamp 3 clamping force $P_{f}$, the punch 4 , the translational moving with a constant velocity, which acts to force the extrusion $P_{e x t}$.

Table 1. Comparative tests of technological Lubricants.

\begin{tabular}{|l|c|c|c|c|}
\hline Lubricant & $P_{s}, \mathrm{kN}$ & $P_{r \max }, \mathrm{kN}$ & $H_{d e}, \mathrm{~mm}$ & $\Delta D, \mathrm{~mm}$ \\
\hline $\begin{array}{l}40 \% \text { aqueous solution. RE-18 with the } \\
\text { addition of 2\% of the nanopowder of copper }\end{array}$ & 31,5 & 51,00 & 13,62 & 1,45 \\
\hline SL-2M TU 0254-044-23763315-2006 & 30,8 & 49,28 & 13,21 & 1,5 \\
\hline Castor oil technical GOST 6757-96[7] & 30,7 & 49,12 & 13,25 & 1,4 \\
\hline
\end{tabular}

The problem of optimization of deep drawing process in ANSYS Workbench solved using the module Static Structural Analysis Systems. Physico-mechanical properties of materials was defined by the parameters: density, young's modulus of elasticity, Poisson's ratio, yield stress (tab. 2).

Table 2. Physical and mechanical properties of sheet steels.

\begin{tabular}{|c|c|c|c|c|}
\hline Material & $\begin{array}{c}\text { Density, } \\
\mathbf{g}^{\text {/cm }} \mathbf{3}\end{array}$ & $\begin{array}{c}\text { The Young's } \\
\text { Modulus, GPa }\end{array}$ & $\begin{array}{c}\text { Poisson's } \\
\text { Ratio }\end{array}$ & $\begin{array}{c}\text { Yield strength, } \\
\text { MPa }\end{array}$ \\
\hline St3kp. GOST 16523-97 [9] & 7,85 & 208 & 0,26 & 195 \\
\hline 08kp. GOST 16523-97[9] & 7,87 & 203 & 0,26 & 196 \\
\hline 06JU. GOST 9045-93 [10] & 7,8 & 200 & 0,26 & 195 \\
\hline
\end{tabular}




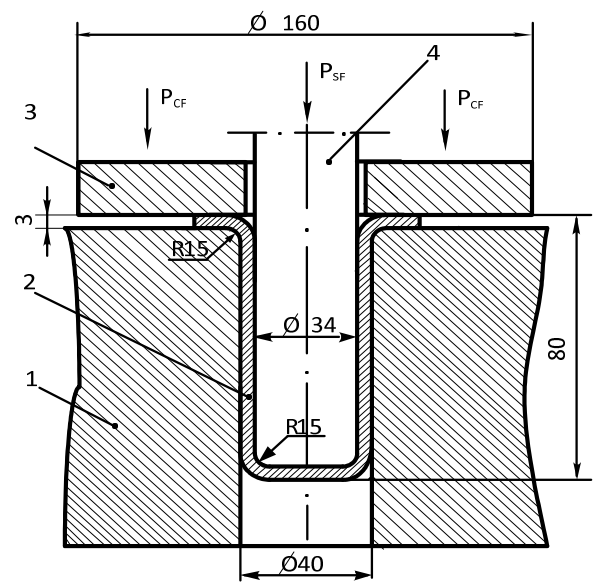

Fig. 2. The geometric parameters of the model die of the tool for deep drawing sheet steels with a clamp: 1 - matrix; 2 - workpiece; 3 - clamp; 4 - punch.

All units in the model were specified type of Frictional connection with the specified friction coefficients received experimentally and is equal to $0,28-0,32$, for the case without the use of lubricant and $0.15-0.16$ in the case of using the lubricant RE-18 with the additives of nano-powders of non-ferrous metals.

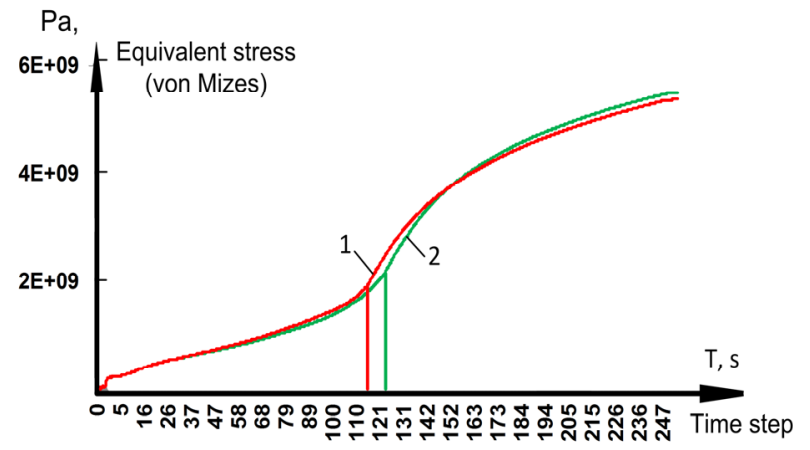

Fig. 3. Increase in total stresses in the samples according to Mises (Equivalent von Mizes Stress) in time: 1-without use, 2- using a -40\% aqueous solution of lubricant RE-18 for deep drawing of sheet steel 08JU

Note: in Fig. 3, the designation 2E + 09 corresponds to $2.109 \mathrm{~Pa}$; in Figure 4a, the designation $1.9747 \mathrm{e} 9$ corresponds to $1.9747 .109 \mathrm{~Pa}$

The results were analyzed by the maximum total stress (Equivalent Stress). The calculations for all the studied steels, revealed the increase of yield stress of sheet steel, reducing the thickness of the bottom of the cylinder of a deformable workpiece and time of movement of the punch to the workpiece gap was $115 \ldots 122$, which corresponds to a further displacement of the punch from 38.3 to $40.6 \mathrm{~mm}$ (Fig. 3).

From Figure 4 it should be noted, that the voltage at the workpiece without lubricant and using $40 \%$ aqueous solution of RE-18 vary considerably. Also changes the thickness of the bottom deforming billets. Noted that the deep hood bottom thickness when dry rubbing decreased from $3 \mathrm{~mm}$ to $2.2 \mathrm{~mm}$ and when lubrication $40 \%$-s ' water solution with $3 \mathrm{~mm}$ to $1.4 \mathrm{~mm}$ in subjects steels. 


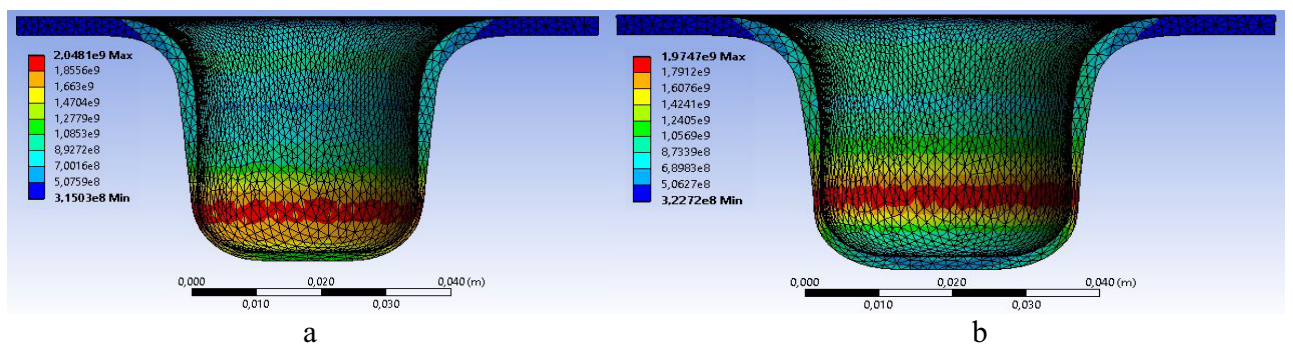

Fig. 4. Plot the distribution of total von Mises stress (Equivalent von Mizes Stress) in the model of sheet steel 08JU at break: a - no lubricant $b$ - using a $40 \%$ aqueous solution of the lubricant RE-18 with the addition of $2 \%$ of the nanopowder of copper.

Based on the results of research of technology of water-soluble lubricant RE-18 with the additives of nano-powders of copper, bronze and zinc during deep drawing sheet steels the following conclusions:

- lubricant RE-18 improves the efficiency of deep drawing process increases the yield strength of the workpiece material to 5.7 to $6 \%$, by thinning the bottom of the workpiece at given geometric parameters of the model due to the formation of the contact units, the matrix -wrought product-tool with an integrated anti-friction films high load capacity and a thickness of 10-30nm;

- lubricant RE-18 has almost the same efficiency at drawing the leaf blanks from steel St3kp, steel 08KP, 08JU due to the proximity of the chemical composition of sample steels and oxide films on the surfaces of these steels;

- to increase the maximum depth of the extrusion before the rupture of the workpiece it is recommended to change the geometrical parameters of the parts and the external conditions used in this process: to optimize the radii, on the die and the punch, the clearance between the punch and the matrix, to change the force on the clamp, and the thickness of the workpiece.

\section{Conclusion}

Hybrid fractal clusters of a water-soluble lubricant RE-18 with built-in nanometric particle powders of non-ferrous metals copper, zinc and bronze generate in tribocharging stamping tool - wrought product made of steel sheet of film on the contact surfaces, protected from adhesion and improve the surface quality of the workpiece.

The use of the system of finite element analysis ANSYS Workbench allows to optimize the deep drawing process of sheet steel with improved surface quality of the workpiece by the regulation of the concentration of the lubricant $\mathrm{RY}-18$, and the radii of the matrix and punch, the clamping force of the workpiece, a clearance between a die and a punch

\section{References}

1. G. I. Shulga, Functional water-soluble lubricant technology for materials processing (Izvestiya vuzov, Severo-Kavkazskiy region, Rostov n/D, 2004)

2. G. I. Shulga, A. O. Kolesnichenko, E. V. Skrynnikov., T. G. Shulga, Vestnik of Don State Technical University 11(10), 1867 (2011)

3. V. E. Isachenkov, E. I. Isachenkov, Forging and stamping production, 12, 18 (1972)

4. D. F. Moore, The Friction and Lubrication of Elastomers (Pergamon, Oxford, USA, 1972) 
5. GOST 5322-2008. Non-automatic weighing instruments. Part 1. Metrological and technical requirements. Tests. Date of introduction 01.01.2010, (STANDARTINFORM, Moscow, 2010)

6. G. I. Shulga, Izvestiya vuzov. Severo-Kavkazskiy region. Technical science, 3-4, 120 (1994)

7. GOST 6757-96 Castor Oil technical. Date of introduction 01.01.1997. (STANDARTINFORM, Moscow, 2011)

8. V. A. Bruyaka, V. G. Fokin, E. A. Soldatova, N. A. Glazunov, I. E. Adeyanov, Engineering analysis in ANSYS Workbench; study guide, part 1. (Samara State Technical University, Samara, 2010)

9. GOST 16523-97 Rjolled sheets from quality and ordinary carbon steelfor general purposes. Specification Date of introduction 01.01.2000. (STANDARTINFORM, Moscow, 2009)

10. GOST 9045-93 Cold-rolled thin sheets of low-carbon steel for cold stamping. Specifications. Date of introduction 01.01.1997. (PPC Publishing standards, Moscow, 2003) 